\title{
The seven-year epidemiological study of legal abortion caused by heart disease, blood disorders, diabetes and hypertension as referred to forensic medicine centers in Fars Province
}

\author{
FATEMEH GHODRATI 1, A, D, E, F, NARJES SAADATMAND², B, D, F, SAEID GHOLAMZADEH ${ }^{3, \text { D, F, }}$ \\ MARZIEH AKBARZADEH $H^{4, A}, \mathbf{C - F}$ \\ ORCID ID: 0000-0002-4491-2437 \\ ${ }^{1}$ Department of Theology, Faculty of Humanities Science College, Yasouj University, Yasouj, Iran \\ ${ }^{2}$ Department of Midwifery, Student Research Committee, School of Nursing and Midwifery, Shiraz University of \\ Medical Sciences, Shiraz, Iran \\ ${ }^{3}$ Legal Medicine Research Center, Legal Medicine Organization, Tehran, Iran \\ ${ }^{4}$ Maternal-Fetal Medicine Research Center, Department of Midwifery, School of Nursing and Midwifery, Shiraz \\ University of Medical Sciences, Shiraz, Iran
}

A - Study Design, B - Data Collection, C - Statistical Analysis, D - Data Interpretation, E - Manuscript Preparation, F - Literature Search, G - Funds Collection

Summary Background. Chronic diseases such as uncontrolled diabetes, some types of heart disease, and hypertension are of the most common risk factors for high risk pregnancies and spontaneous or therapeutic abortions.

Objectives. To investigate the legal abortion caused by heart disease, blood disorders, diabetes and hypertension as referred to forensic medicine centers in Fars Province from 2007 to 2013.

Material and methods. In a retrospective, cross-sectional study, samples consisted of all documents of people referred to forensic medicine centers in Shiraz since 2007 to 2013, comprising of 1664 files. Data collection tools included a demographic forum and the checklist of abortion causes. SPSS.16.0 was applied to analyze the data through descriptive statistical analysis.

Results. The most frequent age group was $25-29$ years at $31.5 \%(n=522)$ and the lowest was over 40 years old at $4.15 \%(n=70)$. The statistical report of the reasons for legal abortion permission were $19 \%(n=63), 24.4 \%(n=81), 10.54 \%(n=35)$, and $8.13 \%(n=27)$ due to heart problems, blood disorders, hypertension, and diabetes mellitus, respectively. Most frequent legal abortion permits by forensic medicine due to maternal causes were between the years of $2011-2012$ at $17.8-28 \%(n=59-93)$. The relationship between legal abortion permission at The Forensic Medicine Center at different years and maternal ages was statistically significant $(p<0.00001)$. Conclusions. The most common prevalent reason of abortion was Blood Disorder -81 patients $(24.4 \%)$ and heart disease -63 cases $(19 \%)$. It is essential that family education and prevention of repeated pregnancies be done with high-risk women. Also, initiation of pregnancy care at lower gestational age in identifying risky pregnancies and timely control of complications must also be undertaken. Key words: heart diseases, diabetes mellitus, hypertension, abortion, legal.

Ghodrati F, Saadatmand N, Gholamzadeh S, Akbarzadeh M. The seven-year epidemiological study of legal abortion caused by heart disease, blood disorders, diabetes and hypertension as referred to forensic medicine centers in Fars Province. Fam Med Prim Care Rev 2019; 21(1): 23-29, doi: https://doi.org/10.5114/fmpcr.2019.82975.

\section{Background}

Insecure abortion is still one of the main reasons for the death of mothers, accounting for $14.5 \%$ of all maternal deaths globally [1].

The General Assembly, attended by the leaders of 189 countries, signed a statement on the eight Millennium Development Goals in 2000, the intent of which was to improve the lives of women, men and children [2]. The agreement demanded a reduction in the world's maternal mortality ratio by 75\% from 1990 to 2015 . Therein, absolute prevention and reduction in maternal mortality was introduced as an indicator of maternal health progress [3]. The maternal mortality ratio is, hence, the most important indicator that reflects the situation of progress.

In most developing countries, mortality, pregnancy-related complications and childbirth are considered as the first causes of death and disability among women aged 15 to 49 years [4]. Abortion in non-standard and illegal conditions is still considered as the first cause of maternal death in developing countries [5]. Abortion is the result of pregnancy termination, usually before the embryo or fetus is capable of independent life (outside the womb) [6]. A WHO meta-analysis shows that the most important direct causes of maternal death are bleeding, high blood pressure, miscarriage and infection. In addition, both postpartum and antepartum depression are considered as the premier pregnancy related complication [7].

In the Islamic Republic of Iran, abortion of a fetus is restricted to certain legal and religious conditions, but at the moment, despite these conditions, a number of people attempt abortion using secret illegal and unhealthy methods that in some cases, come with failure or even serious complications for the mother and fetus [8,9].

When continuation of pregnancy threatens the mother's life or health or exacerbates her disease complications, therapeutic abortion is a solution enabled by legal permission and medical forensic certification. Fetal abortion is not acceptable in Iran and other Islamic religions except for medical conditions or when the health of the mother is at risk [10]. Currently, there are various legislations as to fetal abortion. Moreover, religious, cultural, and moral beliefs are effective in the implementation of abortion law [11]. 
The right to liberty, moral strategy [12] and the right to reproductive health [13] are of the major human rights that are sometimes used as a justification for the presence or absence of abortion supervisory approaches. Annually, the occurrence

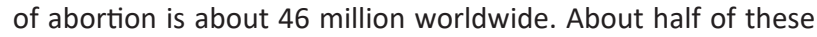
abortions occur in developing countries and are mostly unsafe [14]. There are no official statistics on abortion in Iran; several studies have reported 80,000 abortions per year [15]. Other studies have shown that induced and unsafe abortions engender serious complications such as maternal mortality, uterine rupture and sepsis [16].

At different times, several threatening risk factors come about during pregnancy. The classification of high-risk pregnancies include maternal underlying disease, socioeconomic factors, the history of risk factors in previous pregnancies and the risk factors associated with the current pregnancy that may occur during it [17]. The prevalence of high-risk pregnancies varies from country to country, for example, in northern India, it is $31.4 \%$ [18] and in Tunisia - 59.5\% [19]. Moreover, it is reported that the prevalence of high-risk pregnancies varies in different regions of Iran [20].

Pregnancy is stressful for the mother even in the best conditions. Such maternal stress and anxiety increases when it is combined with unexpected maternal medical problems due to underlying diseases, fetal illnesses that already exist or when it is combined with complications of pregnancy [17]. Women who experience high-risk pregnancy may encounter physical, psychological and socioeconomic consequences imposed by the nature of treatment and the potential need for long-term care at home or in the hospital. They have to adapt their lifestyle to the new situation, and, therefore, it is followed by the negative effects of stress and anxiety for themselves and their family [21].

Some studies that have reviewed the experiences of family planning service providers with regard to the causes of unwanted pregnancy report that issues such as "service provider system problems", "service recipients features" and "capabilities of family planning devices" are reasons for unwanted and unplanned pregnancy. Regarding the problems of service providing systems, some issues such as poor education and inefficient counseling, cultural and linguistic problems in communicating with the recipients of services, the influence of people around pregnant women on their belief and choice of the service recipient, are reported. In addition, disagreement or disapproval of husband in the spouse's use of family planning tools, poor quality of family planning devices in relation to private sector equipment and the lack of providing counseling for men in the centers for the provision of family planning services are also reported as further causes of this problem [22].

\section{What are the major causes of abortion and its prev- alence?}

Valvular heart disease (VHD) is one indication of therapeutic abortion since it endangers the health of both mothers and delivery [23]. Statistically, to the extent of $52 \%$, cyanotic heart disease and pulmonary hypertension are leading causes of maternal mortality [24]. The afflicted should consult with their healthcare provider to prevent pregnancy. Otherwise, they must be under special care if gestation accrued [25].

Gestational diabetes is the most common metabolic disorder in pregnancy. In the United States, it involves about 5 percent of all pregnancy complications. The worldwide number of patients with type 2 diabetes is 285 million, approximately $5 \%$ of the adult population in 2010 . This figure will increase to about 438 million in 2030, [26, 27]. Iran's Ministry of Health reported 7.7 percent as the prevalence of type 2 diabetes among people aged 25 to 64 years in 2008. Diabetic patients are more prone to cardiovascular disease, depression, and kidney and eye disease compared to normal individuals [28]. A review study, which was conducted on the prevalence of GDM in Iran, states that the prevalence of GDM was reported between 1.3 percent and 8.9 percent in different areas in Iran in 2008. Its prevalence was 4.4 percent in women without risk factors in Tehran and 10 percent in women having at least one risk factor [29]. According to the results of another study, Asians were identified as the race at high risk for gestational diabetes. However, there are different statistics due to the variety of races and ethnicities, differences in lifestyle and nutrition, socio-economic status, lack of an equal protocol for diagnosis and screening [30]. Stillbirth (fetal death at or after 20 to 28 weeks of pregnancy), miscarriage, pre-eclampsia, and macrosomia were reported in the studies on patients with gestational diabetes [31].

Hypertension differences were also major causes (prevalence of $5.9 \%$ ) of maternal death during pregnancy [32]. The study conducted by Mettu and Ethiopia reveals that the prevalence of hypertensive disorder was $2.4 \%$ in 2010-2013. The majority of women afflicted (82.6\%) were 18 and 34 years old.

Fetal complications included abortion (10.7\%), preterm birth (31.4\%), and birth death (120.37 cases in 1000 births) [33]. Increased permitted therapeutic abortion leads to transfer of abortion laws from the field of crime to health and welfare [34]. Repeated visits into forensic medicine centers for abortion and lack of similar studies prompted us to do this study. Thus, this study aimed to investigate the legal abortion caused by heart disease, blood disorders, diabetes, and hypertension as referred to forensic medicine centers in Fars Province since 2007 to 2013.

\section{Objectives}

Primary purpose: To investigate the frequency of legal abortion brought about by heart disease, blood disorders, diabetes, and hypertension and others.

Secondary purpose: To investigate the frequency of maternal cause of legal abortion in different parental age groups.

\section{Material and methods}

\section{Study design}

This is a retrospective, cross-sectional study.

\section{Setting}

Forensic medicine centers in Iran, Shiraz within 2007-2013.

\section{Participants and study size}

The study population consisted of 1664 documents of people referred to forensic medicine centers in Shiraz from 2007 to 2013 . About 1325 (79.6\%) listed a fetal cause and 339 documents (20.4\%) showed maternal causes for abortion (the exact causes of maternal causes are clear in seven cases due to personal and judicial appeals).

\section{Variables}

The types of variables encountered in the study included demographic characteristics, causes of abortion that are approved under Iranian law and through forensic center permission to perform (legal permission), mother's addiction and kind of addictive substances (cigarettes, alcohol, medical drugs). Of note, mother's addiction information is not discussed in the article.

\section{Data sources/measurement}

After obtaining written permission from Shiraz University of Medical Sciences and the Department of Forensic organizations, the researcher referred to the clinical examination centers to study the files. Researchers completed the checklists and other parts of the pre-designed questionnaire. The checklists of obstetric variables and the maternal cause of abortion were recorded in the questionnaires. 


\section{Statistical analysis}

SPSS, version 16 , was applied for data analysis using descrip tive statistical analysis. Chi-square was used in order to calculat the correlation of demographic characteristics and parental age a level of 0.05 was considered significant.

\section{Ethical considerations}

This research project was approved by the local Ethics Com mittee of Shiraz University of Medical Sciences and written in formed consents were obtained from all the participants. The research proposal No. was 7754 , and was financially supportec by the students research committee, Shiraz University of Medi cal Sciences.

\section{Results}

In women, the most frequent age group was 25-29 years - at $31.5 \%(n=522)$ and the lowest was over 40 years old - at $4.15 \%$ $(n=70)$. With regard to the husband, the most and least frequent age was between $30-34$ years and below 20 . The highest frequency of educational level was diploma (high school graduation and before entering university) - at $42.6 \%(n=709)$ and illiteracy - at 9.31\% $(n=155)$ in women and husbands, respectively. The statistical report of legal abortion permissions were $19 \%$ ( $n: 63)$, and $24.4 \%$ ( $n: 81)$ due to heart disease and blood disorders, respectively. The most frequent abortion was due to maternal heart disorders in women aged $30-34$ years - at $39.7 \%(n=25)$ and subsequent, the age group of 35-39-year-olds - at 39.2\% $(n=19)$ and, finally, at the age 40 and above - at $22.2 \%(n=14)$. Among other maternal causes, about $10.54 \%$ ( $n: 35)$ obtained legal abortion permission due to hypertension. The most frequent age among mothers with hypertension who had abortions was at the age of 30-34 years - at $37.1 \%(n=13)$ and $35-39$ years - at $34.3 \%(n=12)$, respectively. In addition, about $8.13 \%$ ( $n: 27)$ obtained legal abortion permission due to gestational diabetes. The most frequent age among mothers with gestational diabetes who had abortions was at the age of 30-34 years - at $44.4 \%(n=12)$ and $35-39$ years - at $25.9 \%(n=7)$, respectively (Table 1 ). Of the husbands of wives permitted abortion - at $30.7 \%(n=102)$, most were in the $30-34$ age groups (Table 2$)$.

The most prevalence of legal abortion to maternal causes was within the year 2012 - at $28 \%$ (93 cases) (Figure 1).

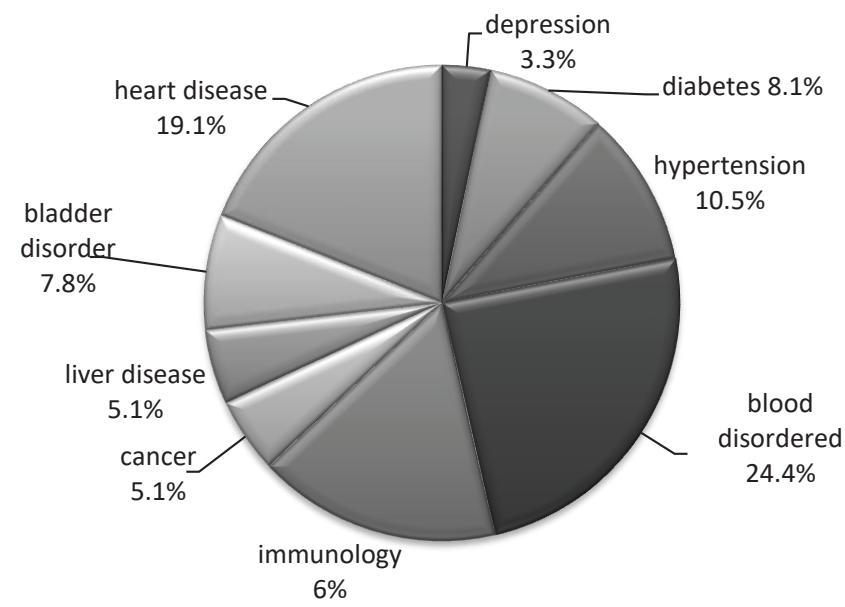

Figure 1. Maternal cause of abortion in the referred to files: Fars Province Forensic Medicine Centers from 2007 to 2013

\section{Discussion}

According to this study, heart disease and hematologic disorders were the most common indications for legal abortion. This was in accordance with a study done by Sadr, wherein cardiovascular disease was the most common (28\%) indication for Legal abortion to maternal causes, and $36 \%$ of all therapeutic abortions was maternal based. The mean age of those who obtained legal abortion was 29.4 years of age [35]. Other research results are consistent with the results of our study. For example, from 205 annual cases of sought legal permission, 144 obtained permission for abortion, of which $88 \%$ were issued for fetal abnormalities and $12 \%$ due to illness of the mother. The most common diseases in the fetus were, brain and skull abnormalities, and in the mothers, cardiovascular diseases and hematologic abnormalities [36]. Although the most common cause of maternal abortion is similar to our study, the prevalence of maternal causes in the study of Astaraki et al. is less than ( $12 \%$ vs 20.4 ). Moreover, Ghadipasha et al. [37] saw $32 \%$ vs $20.4 \%$ and Tofighi saw $36 \%$ vs $20.4 \%$ [38]. Additionally in another study, which was done on 112 pregnant women with heart disease, about 82 cases (73\%) had successful delivery, 32 cases (27\%) had abortion and there was one case with term stillbirth [39].

\begin{tabular}{|c|c|c|c|c|c|c|c|c|c|c|c|}
\hline \multirow{2}{*}{\multicolumn{2}{|c|}{ Mother age }} & \multicolumn{9}{|c|}{ Mother cause } & \multirow[t]{2}{*}{ | Total } \\
\hline & & \multirow{2}{*}{\begin{tabular}{|l|}
$\begin{array}{l}\text { depres- } \\
\text { sion }\end{array}$ \\
3 \\
$27.3 \%$ \\
\end{tabular}} & \multirow{2}{*}{\begin{tabular}{|l|} 
diabetic \\
0 \\
$0 \%$ \\
\end{tabular}} & \multirow{2}{*}{\begin{tabular}{|l|} 
BP \\
1 \\
$2.9 \%$ \\
\end{tabular}} & \multirow{2}{*}{\begin{tabular}{|l|}
$\begin{array}{l}\text { blood dis- } \\
\text { ordered }\end{array}$ \\
14 \\
$17.3 \%$ \\
\end{tabular}} & \multirow{2}{*}{\begin{tabular}{|l|}
$\begin{array}{l}\text { immunol- } \\
\text { ogy }\end{array}$ \\
9 \\
$16.4 \%$ \\
\end{tabular}} & \multirow{2}{*}{\begin{tabular}{|l|} 
cancer \\
0 \\
$0 \%$ \\
\end{tabular}} & \multirow{2}{*}{ 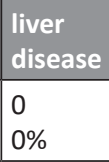 } & \multirow{2}{*}{\begin{tabular}{|l}
$\begin{array}{l}\text { bladder } \\
\text { disorder }\end{array}$ \\
0 \\
$0 \%$ \\
\end{tabular}} & \multirow{2}{*}{$\begin{array}{l}\text { heart } \\
\text { disease }\end{array}$} & \\
\hline Under 20 & \begin{tabular}{|l} 
Count \\
$\%$
\end{tabular} & & & & & & & & & & \begin{tabular}{|l}
27 \\
$8.1 \%$ \\
\end{tabular} \\
\hline $20-24$ & & $\begin{array}{l}1 \\
9.1 \% \\
\end{array}$ & \begin{tabular}{|l|l}
0 \\
$0 \%$ \\
\end{tabular} & $\begin{array}{l}0 \\
0 \%\end{array}$ & $\begin{array}{l}26 \\
32.1 \% \\
\end{array}$ & \begin{tabular}{|l|}
14 \\
$25.5 \%$ \\
\end{tabular} & \begin{tabular}{|l|}
0 \\
$0 \%$ \\
\end{tabular} & \begin{tabular}{|l|}
0 \\
$0 \%$ \\
\end{tabular} & \begin{tabular}{|l|}
0 \\
$0 \%$ \\
\end{tabular} & $\begin{array}{l}2 \\
3.2 \% \\
\end{array}$ & $\begin{array}{l}33 \\
13.0 \% \\
\end{array}$ \\
\hline $25-29$ & & $\begin{array}{l}4 \\
36.4 \%\end{array}$ & $\begin{array}{l}7 \\
25.9 \% \\
\end{array}$ & $\begin{array}{l}3 \\
8.6 \% \\
\end{array}$ & $\begin{array}{l}23 \\
28.4 \%\end{array}$ & $\begin{array}{l}22 \\
40.0 \%\end{array}$ & $\begin{array}{l}1 \\
5.9 \% \\
\end{array}$ & \begin{tabular}{|l}
6 \\
$35.3 \%$ \\
\end{tabular} & $\begin{array}{l}11 \\
42.3 \% \\
\end{array}$ & $\begin{array}{l}3 \\
4.8 \% \\
\end{array}$ & \begin{tabular}{|l}
80 \\
$24.1 \%$
\end{tabular} \\
\hline $30-34$ & & $\begin{array}{l}1 \\
9.1 \%\end{array}$ & $\begin{array}{l}12 \\
44.4 \%\end{array}$ & $\begin{array}{l}13 \\
37.1 \%\end{array}$ & $\begin{array}{l}9 \\
11.1 \%\end{array}$ & $\begin{array}{l}6 \\
10.9 \% \\
\end{array}$ & $\begin{array}{l}1 \\
5.9 \%\end{array}$ & $\begin{array}{l}7 \\
41.2 \%\end{array}$ & $\begin{array}{l}10 \\
38.5 \%\end{array}$ & $\begin{array}{l}25 \\
39.7 \%\end{array}$ & $\begin{array}{l}84 \\
25.3 \%\end{array}$ \\
\hline $35-39$ & & $\begin{array}{l}1 \\
9.1 \% \\
\end{array}$ & $\begin{array}{l}7 \\
25.9 \% \\
\end{array}$ & $\begin{array}{l}12 \\
34.3 \% \\
\end{array}$ & \begin{tabular}{|l|}
6 \\
$7.4 \%$ \\
\end{tabular} & \begin{tabular}{|l|}
4 \\
$7.3 \%$ \\
\end{tabular} & $\begin{array}{l}10 \\
58.8 \% \\
\end{array}$ & $\begin{array}{l}4 \\
23.5 \% \\
\end{array}$ & $\begin{array}{l}3 \\
11.5 \% \\
\end{array}$ & $\begin{array}{l}19 \\
30.2 \% \\
\end{array}$ & $\begin{array}{l}66 \\
19.9 \% \\
\end{array}$ \\
\hline $\begin{array}{l}40 \text { \& up- } \\
\text { per }\end{array}$ & & $\begin{array}{l}1 \\
9.1 \%\end{array}$ & $\begin{array}{l}1 \\
3.7 \%\end{array}$ & $\begin{array}{l}6 \\
17.1 \%\end{array}$ & $\begin{array}{l}3 \\
3.7 \%\end{array}$ & $\begin{array}{l}0 \\
0 \%\end{array}$ & $\begin{array}{l}5 \\
29.4 \%\end{array}$ & $\begin{array}{l}0 \\
0 \%\end{array}$ & \begin{tabular}{|l|}
2 \\
$7.7 \%$ \\
\end{tabular} & $\begin{array}{l}14 \\
22.2 \%\end{array}$ & $\begin{array}{l}32 \\
9.6 \%\end{array}$ \\
\hline Total & & $\begin{array}{l}11 \\
100 \%\end{array}$ & $\begin{array}{l}27 \\
100 \%\end{array}$ & $\begin{array}{l}35 \\
100 \%\end{array}$ & $\begin{array}{l}81 \\
100 \%\end{array}$ & $\begin{array}{l}55 \\
100 \%\end{array}$ & \begin{tabular}{|l}
17 \\
$100 \%$
\end{tabular} & \begin{tabular}{|l}
17 \\
$100 \%$
\end{tabular} & $\begin{array}{l}26 \\
100 \%\end{array}$ & \begin{tabular}{|l}
63 \\
$100 \%$
\end{tabular} & $\begin{array}{l}332 \\
100 \%\end{array}$ \\
\hline
\end{tabular}




\begin{tabular}{|c|c|c|c|c|c|c|c|c|c|c|c|}
\hline \multirow{2}{*}{\multicolumn{2}{|c|}{ Father age }} & \multicolumn{9}{|c|}{ Mother cause } & \multirow[t]{2}{*}{ Total } \\
\hline & & $\begin{array}{l}\text { depres- } \\
\text { sion }\end{array}$ & diabetic & BP & $\begin{array}{l}\text { blood dis- } \\
\text { ordered }\end{array}$ & \begin{tabular}{|l} 
immunol- \\
ogy
\end{tabular} & cancer & \begin{tabular}{|l} 
liver \\
disease
\end{tabular} & \begin{tabular}{|l|} 
urology \\
disorder
\end{tabular} & $\begin{array}{l}\text { heart } \\
\text { disease }\end{array}$ & \\
\hline Under 20 & \begin{tabular}{|l} 
Count \\
$\%$
\end{tabular} & $\begin{array}{l}2 \\
18.2 \%\end{array}$ & $\begin{array}{l}0 \\
0 \%\end{array}$ & $\begin{array}{l}0 \\
0 \%\end{array}$ & $\begin{array}{l}7 \\
8.6 \%\end{array}$ & $\begin{array}{l}1 \\
1.8 \%\end{array}$ & $\begin{array}{l}0 \\
0 \%\end{array}$ & $\begin{array}{l}0 \\
0 \%\end{array}$ & $\begin{array}{l}0 \\
0 \%\end{array}$ & $\begin{array}{l}0 \\
0 \%\end{array}$ & $\begin{array}{l}10 \\
3 \%\end{array}$ \\
\hline $20-24$ & & $\begin{array}{l}2 \\
18.2 \%\end{array}$ & \begin{tabular}{|l|}
0 \\
$0 \%$
\end{tabular} & \begin{tabular}{|l|}
1 \\
$2.9 \%$ \\
\end{tabular} & $\begin{array}{l}15 \\
18.5 \%\end{array}$ & \begin{tabular}{|l|}
8 \\
$14.5 \%$
\end{tabular} & $\begin{array}{l}0 \\
0 \%\end{array}$ & \begin{tabular}{|l|}
0 \\
$0 \%$
\end{tabular} & \begin{tabular}{l|}
1 \\
$3.8 \%$
\end{tabular} & $\begin{array}{l}1 \\
1.6 \%\end{array}$ & \begin{tabular}{|l|}
28 \\
$8.4 \%$ \\
\end{tabular} \\
\hline $25-29$ & & \begin{tabular}{|l|}
2 \\
$18.2 \%$
\end{tabular} & \begin{tabular}{l|l}
1 \\
$3.7 \%$ \\
\end{tabular} & \begin{tabular}{|l|}
1 \\
$2.9 \%$ \\
\end{tabular} & $\begin{array}{l}11 \\
13.6 \%\end{array}$ & \begin{tabular}{|l|}
13 \\
$23.6 \%$
\end{tabular} & $\begin{array}{l}0 \\
0 \%\end{array}$ & $\begin{array}{l}2 \\
11.8 \%\end{array}$ & \begin{tabular}{|l|}
1 \\
$3.8 \%$ \\
\end{tabular} & $\begin{array}{ll}3 \\
4.8 \% \\
\end{array}$ & \begin{tabular}{|l|}
34 \\
$10.2 \%$
\end{tabular} \\
\hline $30-34$ & & $\begin{array}{l}2 \\
18.2 \%\end{array}$ & $\begin{array}{l}11 \\
40.7 \% \\
\end{array}$ & $\begin{array}{l}10 \\
28.6 \% \\
\end{array}$ & $\begin{array}{l}21 \\
25.9 \% \\
\end{array}$ & $\begin{array}{l}20 \\
36.4 \% \\
\end{array}$ & $\begin{array}{l}1 \\
5.9 \% \\
\end{array}$ & \begin{tabular}{|l|}
$71.2 \%$ \\
\end{tabular} & $\begin{array}{l}15 \\
57.7 \% \\
\end{array}$ & $\begin{array}{l}15 \\
23.8 \%\end{array}$ & $\begin{array}{l}102 \\
30.7 \%\end{array}$ \\
\hline $35-39$ & & $\begin{array}{l}3 \\
27.3 \% \\
\end{array}$ & $\begin{array}{l}11 \\
40.7 \% \\
\end{array}$ & \begin{tabular}{|l|l}
14 \\
$40 \%$ \\
\end{tabular} & $\begin{array}{l}18 \\
22.2 \%\end{array}$ & $\begin{array}{l}9 \\
16.4 \%\end{array}$ & $\begin{array}{l}10 \\
58.8 \%\end{array}$ & $\begin{array}{l}6 \\
35.3 \%\end{array}$ & $\begin{array}{l}5 \\
19.2 \%\end{array}$ & $\begin{array}{l}27 \\
42.9 \% \\
\end{array}$ & $\begin{array}{l}103 \\
31 \%\end{array}$ \\
\hline $\begin{array}{l}40 \& \text { up- } \\
\text { per }\end{array}$ & & \begin{tabular}{|l}
0 \\
$0 \%$ \\
\end{tabular} & \begin{tabular}{|l|}
4 \\
$14.8 \%$ \\
\end{tabular} & \begin{tabular}{|l|}
9 \\
$25.7 \%$ \\
\end{tabular} & $\begin{array}{l}9 \\
11.1 \% \\
\end{array}$ & $\begin{array}{l}4 \\
7.3 \% \\
\end{array}$ & $\begin{array}{l}6 \\
35.3 \% \\
\end{array}$ & \begin{tabular}{|l|} 
\\
$11.8 \%$ \\
\end{tabular} & \begin{tabular}{|l} 
\\
$15.4 \%$ \\
\end{tabular} & \begin{tabular}{|l|}
17 \\
$27 \%$ \\
\end{tabular} & $\begin{array}{l}55 \\
16.6 \% \\
\end{array}$ \\
\hline Total & & $\begin{array}{l}11 \\
100 \%\end{array}$ & \begin{tabular}{|l|}
27 \\
$100 \%$
\end{tabular} & \begin{tabular}{|l|}
35 \\
$100 \%$
\end{tabular} & $\begin{array}{l}81 \\
100 \%\end{array}$ & $\begin{array}{l}55 \\
100 \%\end{array}$ & $\begin{array}{l}17 \\
100 \%\end{array}$ & $\begin{array}{l}17 \\
100 \%\end{array}$ & $\begin{array}{l}26 \\
100 \%\end{array}$ & $\begin{array}{l}63 \\
100 \%\end{array}$ & $\begin{array}{l}332 \\
100 \%\end{array}$ \\
\hline
\end{tabular}

The necessity of education as a useful strategy should not be ignored due to the young age pyramid in Iran. Receiving precise recommendations from the experts seems to be required for mothers at risk [36].

In our study, the most frequent cause of abortion permission was gestational diabetes at the age of 30-35 years (37.1\%). Type 2 diabetes makes up about 90 to 95 percent of all those afflicted with diabetes and it usually occurs at over 40 years of age and is considered the most common and important metabolic disease in human [40]. Its long-term complications include cardiovascular disease, stroke, blindness, amputation, and kidney disease [41]. The prevalence of pre-gestational diabetes increased from 3.1 per 1,000 live births in 1996-1998, to 4.7 per 1,000 in 2002-2004 [42]. According to a study done in Denmark, from 1985 to 2003, 165 out of 573 cases with gestational diabetes (29\%) had lost their pregnancy in the first trimester due to spontaneous and therapeutic abortion, stillbirth, neonatal death, or major congenital abnormalities detection [43]. In a retrospective study, about 91 women with gestational diabetes (74 patients with type 1 and 17 women with type 2 diabetes) were examined during their pregnancy with singleton and good perinatal outcome. The result showed that 60 women had abortions due to diabetes (48 women [80\%] with type 1 and 12 [20\%] patients with type 2 diabetes). Suboptimal metabolic control and mothers' age were the most two predisposing factors in the first trimester abortions in women with pre-gestational diabetes. In modern medicine, despite the improvement in metabolic control, diabetes is considered as the strongest factor in the changes of fetus development especially during the first trimester of pregnancy [44].

Another study was conducted on pregnancy with affected neonates $(n=90)$ and pregnancies with normal neonates $(n=209)$ from February 2007 to December 2012 in Kashan. The results showed that in diabetic mothers, the risk of abortion increased during the third and fourth weeks of pregnancy, thus, the incidence of neural tube defects (NTDs) was reported to be 2.33 in 1,000 births. The risk of abortion is associated with diabetes with NTD-affected neonates 4.9 (1.9-12.8) and in obese mothers 5.4 (1.3-21.8) [45]. Thus, considering the proportions of spontaneous losses/abortion in women with type 1 or type 2 diabetes, there is a need for special attention, hence, emphasis has been placed on pre-conception care [46]. Researches show that due to changes in lifestyle and diet of people in different countries, the incidence of diseases such as diabetes and gestational diabetes is increasing, and women with gestational diabetes or who are susceptible to type 2 diabetes, face increased risk in childbirth. Moreover, fetal congenital anomalies have been associated with impairment of blood glucose control [47]. So, by planning educational programs and meeting the educational needs of pregnant women, they can be empowered, their health stan- dards promoted and the problems and illnesses that are at risk mitigated [48]. Also, considering that parietal increase has a direct relationship with maternal and fetal complications, family planning education and prevention of repeated pregnancies is essential [49].

In the present study, about $10.54 \%$ ( $n$ : 35 ) of all listed patients received abortion permission due to hypertension. Most women suffer from pre-eclampsia, eclampsia, and chronic hypertension during their pregnancy and postpartum. Pre-eclampsia and eclampsia mostly occur within the second trimester and rarely up to six weeks after giving birth. Its main cause is still undefined, but appropriate medication can reduce its negative signs and side effects, but pregnancy termination is the final and certain cure.

According to a review study, the prevalence of pre-eclampsia and eclampsia is $4.6 \%(2.7-8.2 \%)$ and $1.4 \%(1-2 \%)$, respectively. Eclampsia and pre-eclampsia are more common in the first pregnancy and in women with obesity, high blood pressure, and diabetes. They are also more prone to perinatal mortality, placental abruption, and maternal cardiovascular disease [50]. In another study done in Kerman within 2009-2011, preeclampsia and heart disease were introduced as the most common direct and indirect factor in maternal death. Preeclampsia and heart disease induce some deficiencies in all stages of pre-gestation, during pregnancy and post-partum [51]. In a cross-sectional study of pregnant women referred to the gynecology department in 103 Tehran hospitals (center of Iran), 5170 patients were interviewed, and 252 had preeclampsia. Herein, the number of spontaneous abortions is associated with the number of would-be mothers afflicted with preeclampsia. The incidence of abortion in patients with pre-eclampsia was 1.28 (1.03-9.91). The results are consistent with that of our study [52]. Another study was conducted on the predictors of abortion in western Iran in Hamedan province from April 2013 to March 2014. The results showed that the chances of abortion for each five years of age increase - at $1.85(1.30-1.92)$ and with abortion history - at 3.43 (2.03-5.79). However, no significant correlation was found between abortion and body mass index, previous birth history, low birth weight, congenital anomalies and high blood pressure [53].

In a study in Iran on 2705 participants, 17\% had experienced at least one illegal abortion. One-third of abortions (33\%) were conducted with indirect providers. Most women (84\%) had experienced abortion complications that had required hospitalization [54]. Hence, according to the registered therapeutic abortion law in Iran in 2005, abortion permission (especially before insufflation of the soul) is issued in the case of serious dangers 
and clinical or medical hazards that threaten her life. In addition, due to maternal psychological problems that endanger both her life and her baby - such as severe depression, or suicide, therapeutic abortion was allowed [55].

Finally, since midwives are known as being an effective member of the health team, and are often in the clinical setting. They can be effective in providing spiritual and health advice (such as control of anxiety and negative thoughts and patterns of proper sleep, exercise and nutrition, relaxation exercise during pregnancy) and increasing the morale aspect of mothers. What is more, pregnancy education to parents can reduce maternal stress and transfer these pressures to other family members [56-58]. In addition, spirituality-centered counseling can be effective in controlling post-abortion depression in high-risk pregnancies and leading to its control. Lastly, pregnancy education to parents can reduce maternal stress and transfer these pressures to other family members and eventually lead to decreased depression and anxiety [59-60].

\section{Limitations of the study}

Deficiencies in the files posed limitations of this study, so that the type of disease (heart disease, blood disorders, and diabetes) was not defined in detail. Furthermore, only the general name of the disorder or the system was encountered. In addition, demographic data, pregnancy history, and socioeconomic status of the parents were not recorded. Finally, the case study was retrospective and due to file defects, it was not possible to complete it.

\section{Strengths of the study}

The strengths of this research is that it made it possible to investigate the long-term interval of legal abortions in married people.

\section{Conclusions}

According to the findings, about $62 \%$ of those who were referred to medical abortion had heart disease, hypertension and diabetes. Physicians or experts' diagnosis and preference is the criteria in this regard. Therefore, studies show that despite the provision of family planning services in urban and rural health centers in Iran, for the prevention of high-risk pregnancies that lead to abortion, and for reducing the incidence of unplanned pregnancy, there is a need for improving the quality of family planning service. Improvement herein will provide counseling, enable husband participation, raise the level of knowledge, improve the attitudes of service providers towards family planning and enhance the quality of family planning devices (34). In addition, mothers need to refer to educational-therapeutic centers to be aware of the physical, mental, spiritual, and religious complications that accompany abortion.

Another point is that the law allows a woman to abort in a situation where the mother's health is at risk, yet this in a context wherein abortion is forbidden in the Muslim country of Iran. Hence, there is also a high degree of precision about the cause of abortion (maternal or fetal), which must be confirmed exactly by three doctors with complete para-clinical documentation.

The implication of this study is the importance of planning for the use of contraceptives for mothers with advanced internal diseases. There is also a need to hold maternity educational courses on maternal and fetal problems in high-risk pregnancies.

Therefore, for identification of high-risk pregnancy and timely control of its complications, it is essential to train families about observing family planning, pregnancy prevention, planning for pregnancy and pre-pregnancy counseling, starting prenatal care during pregnancy and lower gestational age.

Acknowledgements. This article was extracted from the research proposal approved by Shiraz University of Medical Sciences (proposal No. 7754). The study was financially supported by Student Research Committee, Shiraz University of Medical Sciences, Shiraz, Iran and the Research Vice-chancellor of Shiraz University of Medical Sciences. The authors would like to thank the Center for Development of Clinical Research of Nemazee Hospital for data analysis and Dr. Nasrin Shokrpour for editorial assistance.

Source of funding: This work was funded by the Student Research Committee, Shiraz University of Medical Sciences, and Shiraz, Iran. Conflicts of interest: The authors declare no conflicts of interest.

\section{References}

1. Faúndes A, Shah IH. Evidence supporting broader access to safe legal abortion. Int J Gynaecol Obstet 2015; 131(Suppl. 1): S56-S59, doi: 10.1016/j.ijgo.2015.03.018.

2. United Nations General Assembly. United Nations Millennium Declaration. New York: United Nations General Assembly; 2000. Available from URL: http://www.un.org/millennium/declaration/ares552e.htm.

3. Bustreo F, Say L, Koblinsky M, et al. Ending preventable maternal deaths: the time is now. Lancet Glob Health 2013; 1(4): E176-E177.

4. Emamiafshar N, Jalilvand P, Delavar B, et al. National maternal surveillance system. Tehran: Tandis Publication; 2006.

5. Veisi F, Zanganeh M. The causes of illegal abortions and their methods in outpatient Clinics of Kermanshah University of Medical Sciences. IJFM 2012; 18 (1): 47-52 (in Persian).

6. Kunins H, Rosenfield A. Abortion: a legal and public health persective. Annu Rev Public Health 1991; 12: 361-382.

7. Gülmezoglu AM, Lawrie TA, Hezelgrave N, et al. Interventions to reduce maternal and newborn morbidity and mortality. In: Black RE, Laxminarayan R, Temmerman M, et al., eds. Source reproductive, maternal, newborn, and child health: disease control priorities. 3rd ed. Washington (DC): The International Bank for Reconstruction and Development/The World Bank; 2016.

8. Godrati F, Saadatmand N, Dinpazhoh M, et al. Epidemiological study of legal abortion due to fetal defects in the files referred to fars Province Forensic Medicine Centers from 2007 to 2013. Shiraz E-Med J 2016; 17(11): e40023, doi: 10.17795/semj40023.

9. Saadatmand N, Ghodrati F, Zarenezhad M, et al. Legal abortion with maternal causes referred to medico-legal centers in Fars: a seven years review of epidemiological evidence in 2007-2013. Health Science Journal 2016: 10(3): 1-6.

10. Abbasi M, Shamsi Gooshki E, Allahbedashti N. Abortion in Iranian legal system: a review. Iran J Allergy Asthma Immunol 2014; 13(1): $71-84$

11. Taylor M. Women's right to health and Ireland's abortion laws. Int J Gynaecol Obstet 2015; 130(1): 93-97.

12. Rocchi B. Why should the baby live? Human right to life and the precautionary principle. J Med Ethics 2013; 39(5): e6-e10.

13. Zúñiga-Fajuri A. Human rights and the right to abortion in Latin America. Cien Saude Colet 2014; 19(3): 841-846.

14. Shah I, Ahman E. Unsafe abortion in 2008: global and regional levels and trends. Reprod Health Matters 2010; 18(36): 90-101.

15. Rustamnezhad M, Asadzadeh F, Mustafazadeh F, et al. Study on abortion cases referred to the Forensic Medicine Center of Ardebil city. Health and Care Journal 2011; 11(4): 38-42. 
16. Shaikh Z, Abbassi RM, Abbasi S. Morbidity and mortality due to unsafe abortion in Pakistan. Int J Gynecol Obstet 2010; 110(1): 47-49.

17. James DK, Steer PJ, Weiner CP, et al. High risk pregnancy: management options. 4th ed. St. Louis (MO): Elsevier Saunders; 2011 : 76-91.

18. Bharti M, Kumar V, Kaure A, et al. Prevalence and correlates of high risk pregnancy in Rural Haryana: a community based study. Int J Basic Applied Med Sci 2013; 3(2): 212-217.

19. Bouafia N, Mahjoub M, Nouira A, et al. Epidemiology of high risk pregnancy in Sousse, Tunisia. EMHJ 2013; 19(5): 465-473.

20. Pasdar Y, Heidari N, Safari Y, et al. Prevalence of some risk factors in pregnant women. Ir J Obstet Gynecol Infertility 2012; 15(21): 14-23.

21. Matteson PS. Women's health during the childbearing years. New York: Mosby; 2001: 700-703.

22. Peyman N, Oakley D. Married Iranian women's knowledge, attitude and sense of self-efficacy about oral contraceptives: focus group discussion. J Reprod Infertil 2011; 12(4): 281-288.

23. Monteiro AV, Rebelo J, Patricio L, et al. Ten years' experience of pregnancy outcomes in women with cardiac valvulopathies: are valve prostheses worst? J Heart Valve Dis 2015; 24(3): 368-375.

24. Lupton M, Oteng-Ntim E, Ayida G, et al. Cardiac disease in pregnancy Curr Opin Obstet Gynecol 2002; 14(2): 137-143.

25. Bowater SE, Thorne SA. Management of pregnancy in women with acquired and congenital heart disease. Postgrad Med J 2010; 86(1012): 100-105.

26. Bonakdaran S, Taghavi M. Cardiovascular risk factors in type 2 diabetic patients in Mashhad City. Iran J Endocrinol Metab 2010; 12(1): 1-6.

27. Aksu H, Pala K, Aksu H. Prevalence and associated risk factors of type 2 diabetes mellitus in Nilufer District, Bursa, Turkey. Int J Diabetes Metabolism 2006; 14: 98-102.

28. Janus ED, Bunker SJ, Kilkkinen A, et al. Prevalence, detection and drug treatment of hypertension in a rural Australian population: the Greater Green Triangle risk factor study 2004-2006. Intern Med J 2008; 38(12): 879-886.

29. Khoshnniat Nikoo M, Abbaszadeh Ahranjani S, Larijani B. A review on the prevalence of gestational diabetes mellitus (GDM) in different regions of Iran. Iran J Diabetes Lipid Dis 2009; 8(7): 47-56.

30. Ferrara A, Kahn HS, Quesenberry CP, et al. An increase in the incidence of gestational diabetes mellitus: Northern California, 1991-2000. Obstet Gynecol 2004; 103(3): 526-533.

31. Kim JH, Shin HS, Park BK, et al. Impact of prepregnancy body mass index on pregnancy outcome in women with a singleton conceived by assisted reproductive technology and spontaneously conceived pregnancy: a case-control study. J Korean Acad Nurs 2012; 42(4): 517-524 (in Korean).

32. Khan KS, Wojdyla D, Say L, et al. WHO analysis of causes of maternal death: a systematic review. Lancet 2006; 367(9516): 1066-1074.

33. Seyom E, Abera M, Tesfaye M, et al. Maternal and fetal outcome of pregnancy related hypertension in Mettu Karl Referral Hospital, Ethiopia. J Ovarian Res 2015; 8: 10, doi: 10.1186/s13048-015-0135-5.

34. Ahmadi A. Basics of medical abortion and examine it from the perspective of criminal law. J Med Law 2012; 6(20): 115-140.

35. Shahabuddin S. Indications for abortion in diseases where risk of maternal death and fetal abnormalities and diseases that baby to still birth or death shortly after birth leads: Department of Legal Medicine. Circular 2006; 10: 31-43 (in Persian).

36. Astaraki P, Mahmoudi GA, Anbari K, et al. Evaluation of approved and non-approved requests for therapeutic abortion in cases referred to legal medicine organization of Lorestan province in 2013. Yafteh 2015; 17(2): 5-13.

37. Ghadipasha M, Aminian Z. Abortion, therapeutic abortion, criminal abortion: legal medicine. Journal of Kerman University of Medical Sciences 2007: 14(2): 147-152 (in Persian).

38. Tofighi H. Choice of forensic medicine, forensic medicine organization. 4th ed. Tehran: Mehr; 2005: 63-159 (in Persian).

39. Child JS. Fallot's tetralogy and pregnancy prognostication and prophesy. J Am Coll Cardiol 2004; 44(1): 181-183.

40. Shaw JE, Sicree RA, Zimment PZ. Global estimates of the prevalence of diabetes for 2010 and 2030. Diabetes Res Clin Pract 2010; 87: 4-14.

41. Health Quality Ontario. Behavioural interventions for type 2 diabetes: an evidence-based analysis. Ont Health Technol Assess Ser 2009; $9(21): 1-45$.

42. Bell R, Bailey K, Cresswell T, et al. Trends in prevalence and outcomes of pregnancy in women with pre-existing type I and type II diabetes. BJOG 2008; 115(4): 445-452.

43. Nielsen $\mathrm{GL}, \mathrm{M} \varnothing$ ller M, Sørensen $\mathrm{HT}$. $\mathrm{HbA}_{1 \mathrm{c}}$ in early diabetic pregnancy and pregnancy outcomes: a Danish population-based cohort study of 573 pregnancies in women with type 1 diabetes. Diabetes Care 2006; 29(12): 2612-2616.

44. Wender-Ozegowska E, Wróblewska K, Zawiejska A, et al. Threshold values of maternal blood glucose in early diabetic pregnancy - prediction of fetal malformations. Acta Obstet Gynecol Scand 2005; 84(1): 17-25.

45. Talebian A, Soltani B, Sehat M, et al. Incidence and risk factors of neural tube defects in Kashan, Central Iran. Iran J Child Neurol 2015; 9(3): 50-56.

46. McGrogan A, Snowball J, de Vries CS. Pregnancy losses in women with Type 1 or Type 2 diabetes in the UK: an investigation using primary care records. Diabet Med 2014; 31(3): 357-365, doi: 10.1111/dme.12332.

47. Restrepo-Moreno M, Ramírez-Rincón A, Hincapié-García J, et al. Maternal and perinatal outcomes in pregnant women with type 1 diabetes treated with continuous subcutaneous insulin infusion and real time continuous glucose monitoring in two specialized centers in Medellin, Colombia. J Matern Fetal Neonatal Med 2017: 1-5, doi: 10.1080/14767058.2017.1295952.

48. Rahimi-Madiseh M, Rahimi-Madiseh S, Gorji M. Continuing education in nursing and midwifery personnel to develop the human resources strategy. J Med Educ Dev 2010; 1(4): 11-20.

49. Gholamzadeh S, Godrati F, Saadatmand N, et al. The obstetrics and gynecology and genetic counseling of mother with legal abortion had been referred to in Fars Province center since 2007-2013. Shiraz E-Med J 2016; 17(2): e35271, doi: 10.17795/semj35271.

50. Abalos E, Cuesta C, Grosso AL, et al. Global and regional estimates of preeclampsia and eclampsia: a systematic review. Eur J Obstet Gynecol Reprod Biol 2013; 170(1): 1-7, doi: 10.1016/j.ejogrb.2013.05.005.

51. Safizadeh M, Damadi B, Safizadeh H. An epidemiologic study of maternal deaths in the population. Covered by Kerman University of Medical Sciences 2010-2012. 2015; 4(2): 114-120 (in Persian).

52. Sepidarkish M, Almasi-Hashiani A, Maroufizadeh S, et al. Association between previous spontaneous abortion and pre-eclampsia during a subsequent pregnancy. Int J Gynaecol Obstet 2017; 136(1): 83-86.

53. Poorolajal J, Cheraghi P, Cheraghi Z, et al. Predictors of miscarriage: a matched case-control study. Epidemiol Health 2014; 36: e2014031, doi: 10.4178/epih/e2014031.

54. Ranji A. Induced abortion in Iran: prevalence, reasons, and consequences. J Midwifery Womens Health 2012; 57(5): 482-488, doi: 10.1111/j.1542-2011.2012.00159.x.

55. Ghodrati F, Akbarzadeh M. Mother's rights and the therapeutic abortion according to Islam. Biomed Rev: J Basic Appl Med Sci 2016; 3(1): 6-12.

56. Akbarzadeh $\mathrm{M}$, Dokuhaki $\mathrm{A}$, Joker $\mathrm{A}$, et al. Teaching attachment behaviors to pregnant women: a randomized controlled trial of effects on infant mental health from birth to the age of three months. Ann Saudi Med 2016; 36(3): 175-183, doi: 10.5144/0256-4947.2016.175. 
57. Dokuhaki A, Akbarzadeh M, Pishva N, et al. A study of the effect of training pregnant women about attachment skills on infants motor development indices at birth to four months. Fam Med Prim Care Rev 2017; 19(2): 114-122, doi: https://doi.org/10.5114/ fmpcr.2017.67864.

58. Setodeh S, Zare N, Akbarzadeh M. A study of the efficacy of fathers' attachment training on paternal-fetal attachment and parental anxiety. Fam Med Prim Care Rev 2017; 19(4): 393-398.

59. Akbarzadeh M, Rafiee B, Asadi N, et al. Comparative effect of attachment and relaxation training on perception of fetal movement and mother's anxiety in Primiparous women: a randomized controlled study. Trends Med Res 2016; 11(2): 62-68.

60. Mokhtaryan T, Yazdanpanahi Z, Akbarzadeh M, et al. The impact of Islamic religious education on anxiety level in primipara mothers. J Family Med Prim Care 2016; 5: 331-337.

Tables: 0

Figures: 1

References: 60

Received: 28.05.2017

Reviewed: 13.06 .2017

Accepted: 3.10 .2018

Address for correspondence:

Marzieh Akbarzadeh, MSc

Maternal-Fetal Medicine Research Center

Department of Midwifery

School of Nursing and Midwifery

Shiraz University of Medical Sciences

Shiraz

Iran

Tel.: 0711-6474250

E-mail: akbarzadm@sums.ac.ir 